\title{
Enhanced Neuronal Activity in the Medial Prefrontal Cortex during Social Approach Behavior
}

\author{
Eunee Lee, ${ }^{1 \star}$ IIssac Rhim, ${ }^{1 \star}$ Jong Won Lee, ${ }^{1}$ Jeong-Wook Ghim, ${ }^{1}$ Seungjoon Lee, ${ }^{1,2}$ Eunjoon Kim, ${ }^{1,2}$ \\ and Min Whan Jung ${ }^{1,2}$ \\ ${ }^{1}$ Center for Synaptic Brain Dysfunctions, Institute for Basic Science, Daejeon, 305-701 Korea, and 2Department of Biological Sciences, Korea Advanced \\ Institute of Science and Technology, Daejeon, 305-701 Korea
}

\begin{abstract}
Although the medial prefrontal cortex ( $\mathrm{mPFC}$ ) is known to play a crucial role in rodent social behavior, little is known about mPFC neural correlates of social behavior. In the present study, we examined single-neuron activity in the mPFC of mice performing a modified version of the three-chamber test. We found that a subset of mPFC neurons elevate discharge rates when approaching a stranger mouse but not when approaching an inanimate object or an empty chamber. Our results reveal mPFC neural activity that is correlated with social approach behavior in a widely used social-interaction paradigm. These findings might be helpful for future investigations of $\mathrm{mPFC}$ neural processes underlying social interaction in health and disease.
\end{abstract}

Key words: in vivo recording; $\mathrm{mPFC}$; object recognition; social interaction; three chamber test

\section{Significance Statement}

Although the prefrontal cortex is known to play a crucial role in rodent social behavior, little is known about prefrontal neural correlates of social behavior. This study shows that the activity of a subset of prefrontal neurons increases in association with social approach behavior during a three-chamber test - a widely used behavioral paradigm. Such responses might be a signature of prefrontal neural processes underlying social approach behavior.

\section{Introduction}

Mouse models of social dysfunction are widely used to investigate neural mechanisms underlying various neuropsychiatric diseases, such as autism spectrum disorders (ASDs), depression, and schizophrenia (Bey and Jiang, 2001; Yang et al., 2011; Ting et al., 2012; Kleijer et al., 2014; Lombardi et al., 2015; Kazdoba et al., 2016). Previous studies have found that the medial prefrontal cortex (mPFC) plays a crucial role in mouse social behavior. A disturbed excitatory and inhibitory balance in the $\mathrm{mPFC}$ has been shown to induce social dysfunction (Yizhar et al., 2011). Social stress causes reduced mPFC neural activity and social avoidance, effects that can be reversed by ketamine treatment, optogenetic stimulation of mPFC neurons, or optogenetic modulation of

Received Jan. 28, 2016; revised April 20, 2016; accepted May 18, 2016.

Author contributions: E.L., J.W.L., J.-W.G., E.K., and M.W.J. designed research; E.L. and J.W.L. performed research; S.L. contributed unpublished reagents/analytic tools; E.L. and I.R. analyzed data; E.K. and M.W.J. wrote the paper.

This work was supported by Institute for Basic Science Grants IBS-R002-D1 (E.K.) and IBS-R002-G1 (M.W.J.).

*E.L. and I.R. contributed equally to this work.

The authors declare no competing financial interests.

Correspondence should be addressed to either Dr. Min W. Jung or Dr. Eunjoon Kim, Center for Synaptic Brain Dysfunctions, Institute for Basic Science, and Department of Biological Sciences, Korea Advanced Institute of Science and Technology, Kuseong-dong, Yuseong-ku, Daejeon 305-701, Korea. E-mail: mwjung@kaist.ac.kr, kime@kaist.ac.kr.

DOI:10.1523/JNEUROSCI.0307-16.2016

Copyright $\odot 2016$ the authors $\quad 0270-6474 / 16 / 366926-11 \$ 15.00 / 0$ dopaminergic projections to the mPFC (Covington et al., 2010; Li et al., 2010; Chaudhury et al., 2013; Lee et al., 2015). In addition, functional alterations of the $\mathrm{mPFC}$ have been observed in mouse models of ASDs that show impaired social interactions. For instance, reduced inhibitory synaptic transmission and decreased NMDA receptor function have been demonstrated in the mPFC of neuroligin-2- and Shank3-deficient mice, respectively (Duffney et al., 2015; Liang et al., 2015). Moreover, an NMDA receptor antagonist has been shown to normalize suppressed mPFC neural activity in mice lacking the excitatory postsynaptic adapter protein IRSp53 and rescue their associated social deficits (Chung et al., 2015).

Although mounting evidence implicates the mPFC in the regulation of social behavior, $\mathrm{mPFC}$ neural correlates of social interaction are poorly understood (Jodo et al., 2010). We addressed this issue in the present study by examining the activity of mPFC neurons in mice during a three-chamber test (Crawley, 2004), which is widely used to measure social dysfunction in animal models of ASDs (Won et al., 2012; Huang et al., 2014; Chung et al., 2015), schizophrenia (Del Pino et al., 2013; Nguyen et al., 2014), and other neurodevelopmental disorders (Grayton et al., 2013; Barnes et al., 2015). In the three-chamber test, a subject mouse is allowed to explore two opposing chambers containing another mouse (social stimulus) or an inanimate object (nonsocial stimulus), and the relative amount of time spent exploring 
the social versus nonsocial target is used as an index of social preference. A caveat to the use of this index for assessing social behavior is that the extent to which the response to a salient stimulus - whether social or nonsocial-accounts for the social target-preferring behavior is unknown. Also unknown is what makes a "social" stimulus social. It could be the target animal's movement, odor, or sound, or some combination of these factors. A previous study has shown that olfactory cues are sufficient to elicit social approach behaviors in mice (Ryan et al., 2008). However, it is possible that other sensory cues, or their combinations with olfactory cues, contribute to social approach behaviors. Clearly, additional studies are necessary to clarify these issues. Nevertheless, given the widespread use of the threechamber test in examining mouse social behavior, it would be informative to examine $\mathrm{MPFC}$ neural activity in the task. As a first step toward understanding $\mathrm{MPFC}$ neural correlates of social behavior, we examined mPFC neuronal activity in mice subjected to a modified version of the three-chamber test. We found that the discharge rates of a subset of MPFC neurons increased in the test mouse during the approach to a social target.

\section{Materials and Methods}

\section{Animals}

C57B/6J male mice (13-15 weeks old, $n=6$ ) were used in all experiments. Mice were maintained with access to food and water ad libitum under a $12 \mathrm{~h}$ light/dark cycle, and their behaviors were examined during the dark phase of the cycle. All animal care and experimental procedures were performed in accordance with protocols approved by the directives of the Animal Care and Use Committee of Korea Advanced Institute of Science and Technology (approval number KA2013-04).

\section{Linear chamber test}

The conventional three-chamber apparatus (Crawley, 2004) was modified to a linear one $(45 \times 10 \times 21 \mathrm{~cm})$ without dividing walls to allow single-unit recording, to minimize exploration of unnecessary areas, and to increase the number of visits to the targets (Fig. 1A). Two removable chambers (target chambers; $10 \times 10 \times 20 \mathrm{~cm}$ ) were placed at both ends of the apparatus. Each target chamber contained a stranger mouse (129/ Sv, male, 12-16 weeks old; social stimulus), an inanimate object (nonsocial stimulus), or nothing (empty chamber). A nonmoving bobble-head doll $(\sim 4 \times 3 \times 7 \mathrm{~cm}$; Fig. $1 \mathrm{~A})$ was used as the inanimate object throughout the experiments. The apparatus was made of translucent acrylic walls $(0.5 \mathrm{~cm}$ thick). The lower $10 \mathrm{~cm}$ of the target-chamber wall facing the other end of the apparatus was barred with 1-cm-spaced thin metal wires to allow the subject mouse to interact with the target.

The daily experiment consisted of three experimental sessions (Fig. $1 A$ ). The animal was first placed in the apparatus and allowed to explore the apparatus freely for $10 \mathrm{~min}$ with both chambers containing no object or animal (session 1: habituation or E-E session; empty chamber, E). Then, a stranger mouse (social stimulus, $\mathrm{S}$ ) and the inanimate object (nonsocial stimulus, $\mathrm{O}$ ) were placed in the chambers with their left/right locations randomly determined. The subject mouse was allowed to explore the targets freely for $10 \mathrm{~min}$ during the second experimental session (first S-O session). The positions of the two targets were then swapped, and the subject mouse was allowed to explore the targets for another 10 min in the third experimental session (second S-O session). The same stranger mouse was used for both S-O sessions. The second S-O session was designed to distinguish social target-dependent neural activities from spatial location (left/right)-dependent ones. The subject mouse was removed from the apparatus and placed on an elevated platform outside the apparatus between successive sessions (intersession intervals $<1$ $\min$ ). Additionally, before and after the three experimental sessions, the subject mouse was placed on the platform for $5 \mathrm{~min}$ to check the stability of unit signals. Because social isolation is known to increase social interaction (Crawley, 2004), each animal was tested with a 4 day interval between successive experiments. Each mouse was tested in 2-10 experiments and exposed to a new stranger mouse in each experiment.

\section{Single-unit recording}

An array of microdrives (Harlan 4-drive; Neuralynx) carrying four tetrodes was implanted in the right $\mathrm{mPFC}(1.7 \mathrm{~mm}$ anterior, $0.3 \mathrm{~mm}$ lateral from bregma, and $1.8-2.5 \mathrm{~mm}$ ventral from the brain surface) under ketamine anesthesia. After 1 week of recovery from surgery, tetrodes were gradually lowered and unit signals were recorded from the prelimbic cortex. Unit signals were amplified 10,000×, filtered between 600 and $6000 \mathrm{~Hz}$, digitized at $32 \mathrm{kHz}$, and stored on a personal computer using a Cheetah data acquisition system (Neuralynx). Tetrodes were lowered by $42.5 \mu \mathrm{m}$ after each daily experiment so that different units were recorded across successive experiments. The anatomical location of each recorded unit was determined based on the location of a marking lesion (histological examination of $40 \mu \mathrm{m}$ coronal brain sections under a light microscope) and the advancement history of the corresponding tetrode. A digital camera was mounted on the ceiling $(100 \mathrm{~cm}$ above the center of the apparatus) to monitor the animal's behavior, and video images were recorded with Ethovision XT 10.1 (Noldus). Spike clustering was performed offline using MClust (A. D. Redish, University of Minnesota, Minneapolis, MN). Only well isolated unit clusters were included in the analysis ( $L$ ratio $<0.1$, isolation distance $>25$ ). Both putative pyramidal cells and putative interneurons were included in the analysis.

\section{Analysis}

Interaction with a target. Video images were analyzed offline with Ethovision XT 10.1. Target nose-poke, in-zone entry, and facing a target were quantified as measures of the interaction with a target. The onset of target nose poke was defined as when the subject mouse's nose (tracked by Ethovision) entered the $12 \times 12 \mathrm{~cm}$ area in the video image covering the wired section of the target chamber wall ( $1 \mathrm{~cm}$ margin from each side of the $10 \times 10 \mathrm{~cm}$ square). A valid nose-poke trial was defined as an incidence of target nose poke for $>1$ $s$ with an interval from the previous nose poke trial $>2 \mathrm{~s}$. In-zone entry was scored when the center point of the subject mouse (tracked by Ethovision) entered the $10 \times 10 \mathrm{~cm}$ area of the floor adjacent to the chamber; Fig. $1 \mathrm{~A}$ ). A valid in-zone trial was defined as a $>1 \mathrm{~s}$ visit of the in-zone area with an interval from the previous visit $>2 \mathrm{~s}$ (center of the body was used). Facing a target was defined as when the projection of the forward orientation vector of the mouse (determined using nose and body coordinates) passed through a chamber in the video image.

Neuronal firing rate. Trials were divided into six groups according to the session $(3 \times)$ and spatial (right or left) location $(2 \times)$. Trials were aligned to the onset of target nose poke or in-zone entry for all valid trials, and spike density functions (SDFs) were constructed by applying a Gaussian kernel $(\sigma=50 \mathrm{~ms})$ to each spike. For each neuron, maximum firing rates during the first $1 \mathrm{~s}$ period after nose-poke onset or in-zone entry were obtained for six SDFs, and the highest of them was used to normalize each SDF. Spike data during the entire nose-poke period was included in the analysis, but similar results were obtained when spike data during the first $1 \mathrm{~s}$ of the nose-poke period was analyzed (data not shown). For the analysis of spatial firing rate, the center chamber was divided into nine zones $(5 \times 10 \mathrm{~cm}$ each $)$ along the longitudinal axis, and the mean spatial firing rate (the number of spikes divided by occupancy time) was calculated for each zone for each neuron. Spatial firing rates were normalized to the highest of the nine zone firing rates for each neuron.

Discrimination index. The discrimination index ( $d$ '; Macmillan and Creelman, 2004; Latimer et al., 2015) was used to compare levels of neuronal responses for two targets in a given session. $d^{\prime}$ was defined as follows:

$$
d^{\prime}=\frac{\mu_{1}-\mu_{2}}{\sqrt{\frac{1}{2}\left(\sigma_{1}^{2}+\sigma_{2}^{2}\right)}}
$$

where $\mu$ and $\sigma$ represent mean and SDs, respectively, of neuronal firing rate during valid nose-poke or in-zone trials. For the S-O sessions, $\mu_{1}$ and $\mu_{2}$ represent mean firing rates for social and object targets, respectively, and positive and negative $d^{\prime}$ values indicate preferential firing toward the social and objet target, respectively. For the E-E session, $\mu_{1}$ and $\mu_{2}$ represent mean firing rates for left and right targets, respectively. Three $d^{\prime}$ values were calculated for all three experimental sessions (E-E, first S-O, and second S-O) for each neuron. 
A
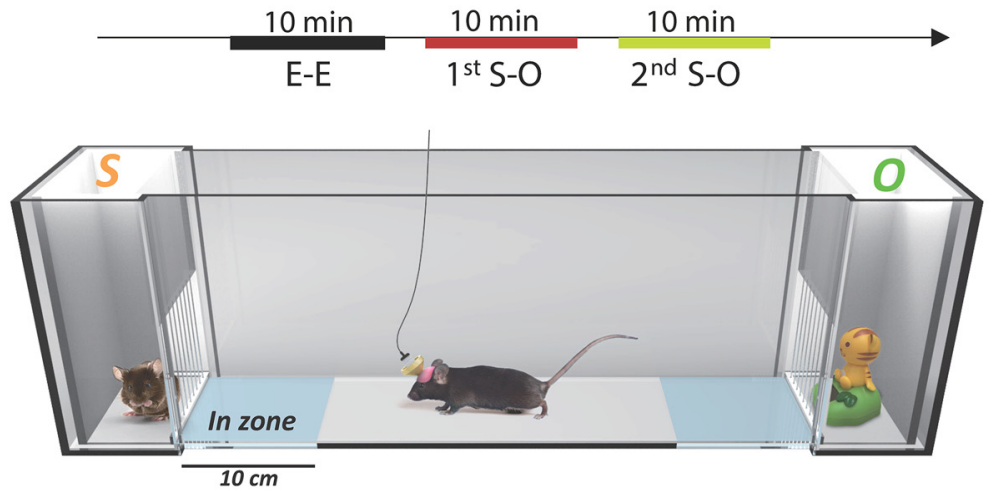

B

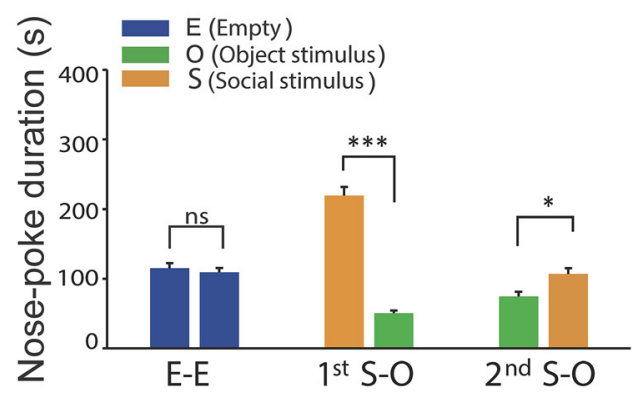

D

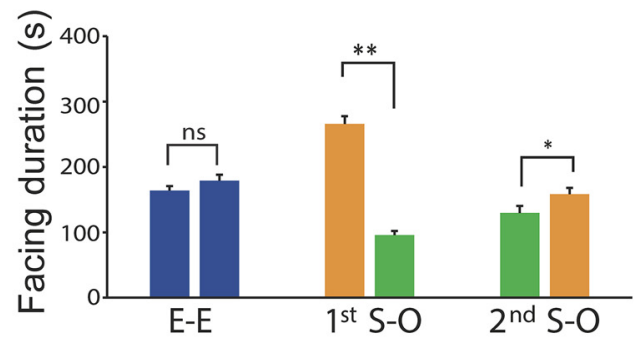

$\mathbf{F}$

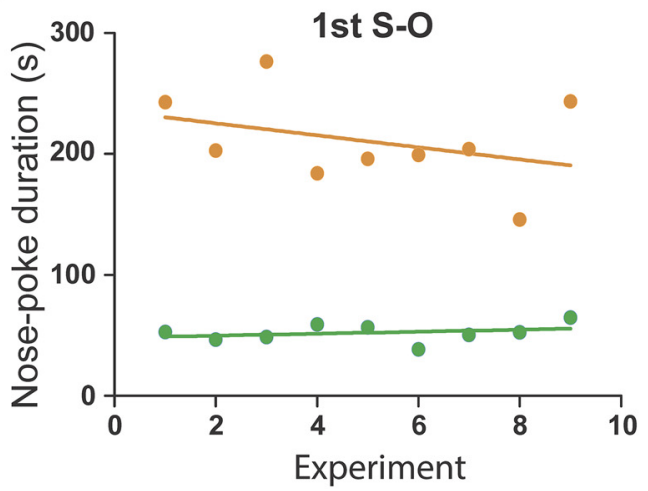

C

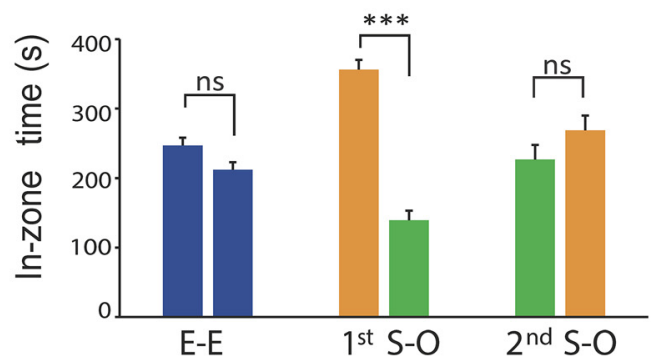

E

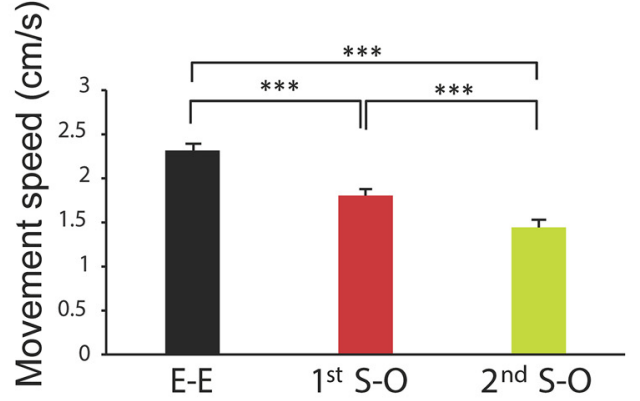

G

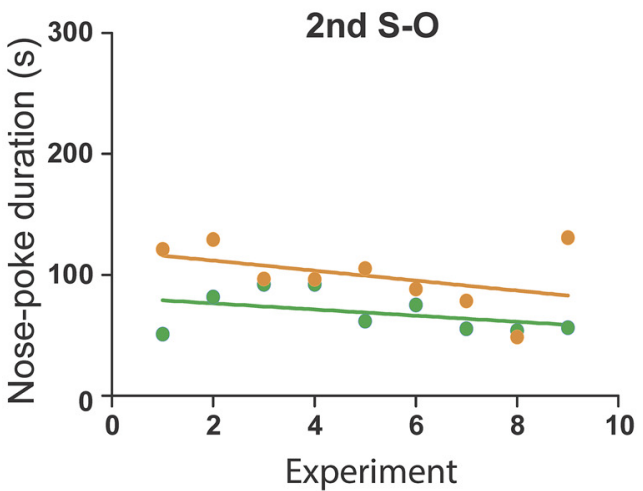

Figure 1. Preferential interaction with a social target in the linear chamber apparatus. $A$, Experimental scheme. Mice were subjected to three 10-min exploratory sessions in the linear chamber apparatus. E-E, Habituation session (both chambers were empty); first $S-0$, the first social interaction session [a stranger mouse-containing chamber (S) versus an inanimate object-containing chamber (0)]; and second S-0, the second social interaction session (the stranger mouse and the inanimate object swapped their positions). $\boldsymbol{B}-\boldsymbol{D}$, Preferential interaction with the social target, as measured by nose-poke $(\boldsymbol{B})$, in-zone $(\boldsymbol{C})$, and facing $(\boldsymbol{D})$ durations (44 experiments, 6 mice; ${ }^{*} p<0.05,{ }^{* *} p<0.01,{ }^{* * *} p<0.001$; ns, not significant; two-way ANOVA with Tukey's post hoc test). $\boldsymbol{E}$, Decreased movement speed (total distance/recording time) across sessions ( $\left.{ }^{* * *} p<0.001\right) . \boldsymbol{F}, \mathbf{G}$, Total nose-poke duration per session across successive experiments. Nose-poke durations for the social (orange) and object (green) stimulus are shown separately for the first $(\boldsymbol{F})$ and second $(\boldsymbol{G}) \mathrm{S}-0$ sessions. The lines were determined with linear regression. None of them showed a significant relationship ( $p$ values of the slopes $>0.05$ ).

\section{Statistical tests}

For the analysis of behavioral data, two-way repeated-measures ANOVA was used to examine effects of stimulus type (social vs nonsocial) and session (first vs second S-O) on animal's approach behaviors (durations of nose poke, in-zone stay, and facing a target), and the repetitive measurement one-way ANOVA was used to compare animal's movement speeds across the three experimental sessions. Student's $t$ test was used to compare the indices of approach behaviors for the left and right targets 
during the habituation (E-E) session. For the analysis of neural data, two-way ANOVA was used to examine the effects of stimulus type (social, object, and empty) and location (left vs right) on neural activities, and one-way ANOVA was used to compare neuronal discrimination index $\left(d^{\prime}\right)$ across the three experimental sessions. Three-way repeatedmeasures ANOVA was also used to examine effects of stimulus type, stimulus location, and session sequence on neural activities. Student's $t$ test was used to test whether neuronal discrimination index $\left(d^{\prime}\right)$ was significantly different from zero. Tukey's test was used in all post hoc analyses after ANOVA. All statistical tests were two-tailed tests. A $p$ value $<0.05$ was used as the criterion for a significant statistical difference, and all data were expressed as mean \pm SEM unless noted otherwise.

\section{Results}

\section{Behavior}

Six mice were tested in 44 experiments, with each consisting of three sessions. Social preference was assessed by comparing the amount of time spent investigating a social versus a nonsocial object stimulus, determined by monitoring nose poking and facing the stimulus and occupation of its in-zone area (Fig. 1A). During the habituation session (session 1), in which both chambers were empty (E-E), mice showed no tendency to preferentially explore the left or right chamber, measured as nose-poke duration $(p=0.518)$, facing duration $(p=0.200)$, and in-zone duration ( $p=0.058 ; n=44$; paired $t$ test). However, mice showed a strong preference for the social stimulus during the first $\mathrm{S}-\mathrm{O}$ session (session 2), which was substantially reduced during the second $\mathrm{S}-\mathrm{O}$ session (session 3; $n=44$; two-way repeatedmeasures ANOVA). The results of ANOVAs (expressed as $F$ values) and post hoc Tukey's test (first vs second session) for each of the three measured parameters can be summarized as follows (Fig. 1B-D): (1) nose-poke duration: main effect of stimulus type, $F_{(1,86)}=48.58(p<0.001)$; main effect of session, $F_{(1,86)}=$ $40.17(p<0.001)$; stimulus $\times$ session interaction, $F_{(1,86)}=204.0$ $(p<0.001)$; $\mathrm{S}$ versus $\mathrm{O}$ during the first $\mathrm{S}-\mathrm{O}$ session, $p<0.001$; $\mathrm{S}$ versus $\mathrm{O}$ during the second $\mathrm{S}-\mathrm{O}$ session, $p=0.011$; (2) facing duration: main effect of stimulus type, $F_{(1,86)}=34.91(p<$ $0.001)$; main effect of session, $F_{(1,86)}=30.40(p<0.001)$; stimulus $\times$ session interaction, $F_{(1,86)}=184.4(p<0.001)$; $\mathrm{S}$ versus $\mathrm{O}$ during the first $\mathrm{S}-\mathrm{O}$ session, $p<0.001$; $\mathrm{S}$ versus $\mathrm{O}$ during the second S-O session, $p=0.048$; and (3) in-zone duration: main effect of stimulus type, $F_{(1,86)}=17.67(p=0.004)$; main effect of session, $F_{(1,86)}=0.011(p=0.751)$; stimulus $\times$ session interaction, $F_{(1,86)}=62.80(p<0.001)$; $\mathrm{S}$ versus $\mathrm{O}$ during the first $\mathrm{S}-\mathrm{O}$ session, $p<0.001$; $\mathrm{S}$ versus $\mathrm{O}$ during the second $\mathrm{S}-\mathrm{O}$ session, $p=0.387$. As shown in Figure $1 E$, the movement speed of mice decreased progressively across the three sessions $(n=44)$, as determined by repeated measures one-way $\operatorname{ANOVA}\left(F_{(2,86)}=62.54, p<0.001\right)$ and Tukey's post hoc test (E-E vs first S-O, $p<0.001$; E-E vs second S-O, $p<0.001$; first $\mathrm{S}-\mathrm{O}$ vs second $\mathrm{S}-\mathrm{O}, p<0.001)$, suggesting that the reduced social interaction during the second relative to the first $\mathrm{S}-\mathrm{O}$ session is likely attributable to habitation. We found no significant change in nose-poke duration across successive experiments (linear regression, $p>0.05$ ), likely because we used a new stranger mouse for each experiment (Fig. $1 F, G$ ).

\section{Neuronal activity during nose poking}

We recorded 248 well isolated units from the prelimbic and infralimbic cortices, with the majority recorded from the prelimbic cortex. Of these, neurons that emitted spikes during all three experimental sessions (E-E, first S-O, and second S-O) with overall mean discharge rates $>0.5 \mathrm{~Hz}$ during the nose-spoke period were included in the analysis (176 of 248 units; Table 1). Figure 2,
Table 1. Acquired cell information

\begin{tabular}{|c|c|c|c|c|c|c|}
\hline $\begin{array}{l}\text { Mouse } \\
\text { identification } \\
\text { number }\end{array}$ & $\begin{array}{l}\text { No. of } \\
\text { experiments }\end{array}$ & $\begin{array}{l}\text { Recorded } \\
\text { units }\end{array}$ & $\begin{array}{l}\text { Analyzed } \\
\text { units }\end{array}$ & $\begin{array}{l}\text { Social- } \\
\text { selective } \\
\text { units }\end{array}$ & $\begin{array}{l}\text { Object- } \\
\text { selective } \\
\text { units }\end{array}$ & $\begin{array}{l}\text { Empty- } \\
\text { selective } \\
\text { units }\end{array}$ \\
\hline
\end{tabular}

\begin{tabular}{crrrrrr}
\hline Nose poking & & & & & & \\
1 & 9 & 32 & 15 & 2 & 0 & 1 \\
2 & 2 & 10 & 9 & 0 & 0 & 3 \\
3 & 10 & 43 & 31 & 3 & 3 & 7 \\
4 & 11 & 68 & 48 & 2 & 1 & 6 \\
5 & 11 & 69 & 51 & 11 & 2 & 7 \\
6 & 2 & 26 & 22 & 1 & 0 & 4 \\
Total & 45 & 248 & 176 & 18 & 6 & 28 \\
In zone & & 32 & 15 & 2 & 3 & 1 \\
1 & 9 & 10 & 9 & 2 & 1 & 0 \\
2 & 2 & 43 & 31 & 4 & 9 & 4 \\
3 & 10 & 68 & 48 & 2 & 9 & 5 \\
4 & 11 & 69 & 51 & 14 & 12 & 2 \\
5 & 11 & 26 & 22 & 0 & 7 & 2 \\
6 & 2 & 248 & 176 & 24 & 41 & 14 \\
Total & 45 & & & & & \\
\hline
\end{tabular}

$A$ and $B$, depicts an example of elevated neuronal activity after nose poking directed toward the social target but not toward other (object or empty) targets. An analysis of nose-pokeassociated neural activity of all neurons $(n=176)$ indicated elevated responses to the social relative to the nonsocial target during the first S-O session $\left(d^{\prime}=0.312 \pm 0.078\right.$; $t$ test, $\left.p<0.001\right)$ but not during the second S-O session $\left(d^{\prime}=-0.095 \pm 0.066 ; t\right.$ test, $p=0.149$; Fig. $2 C, D)$. The discrimination index $\left(d^{\prime}\right)$ of the first S-O session was also significantly greater than those of E-E and second $\mathrm{S}-\mathrm{O}$ sessions, as determined by one-way ANOVA $\left(F_{(2,175)}=13.84, p<0.001\right)$ and Tukey's post hoc test (E-E vs first $\mathrm{S}-\mathrm{O}, p<0.001$; E-E vs second $\mathrm{S}-\mathrm{O}, p=0.918$; first $\mathrm{S}-\mathrm{O}$ vs second $\mathrm{S}-\mathrm{O}, p<0.001$; Fig. $2 D$ ). As expected, neural discrimination was higher for both first and second S-O pairs compared with E-E pairs (greater absolute $d^{\prime}$ values), as determined by one-way ANOVA $\left(F_{(2,175)}=15.49, p<0.001\right)$ and Tukey's post hoc test (E-E vs First S-O, $p<0.001$; E-E vs second S-O, $p=0.011$; first $\mathrm{S}-\mathrm{O}$ vs second $\mathrm{S}-\mathrm{O}, p=0.021$; Fig. $2 E$ ).

We categorized the 176 neurons according to their responses to different stimulus types (social, object, and empty targets). To control for neuronal responses to spatial location (left vs right), we performed a two-way ANOVA (main factors, stimulus type, and spatial location) and selected those neurons that fired discriminately across stimulus types (Tukey's post hoc test). The results are summarized as a Venn diagram (Fig. 3A). As shown, diverse target-dependent responses were observed. Some discriminated only between two different targets (object versus empty, $n=10$; social vs object, $n=6$; and social vs empty, $n=18$ ), some discriminated one type of stimulus from the other two (object vs others, $n=10$; social vs others, $n=22$; empty vs others, $n=31$ ), some discriminated all three types of stimulus from each other $(n=5)$, and others showed no significantly different firing pattern between any two types of stimulus $(n=74)$.

Of the 176 mPFC neurons, 27 (15.3\%) showed significant differences in social-versus-object and social-versus-empty responses (Fig. $3 A, B$ ). Of these, those that showed consistently higher or lower firing rates to the social target compared with object and empty targets, constituting $13.6 \%$ (24 of 176) of all neurons tested, were determined to be social target-selective neurons (Fig. 3B, neurons in the first and third quadrants). The vast majority ( 23 of $24 ; 95.8 \%$ ) of social target-selective neurons ex- 
A

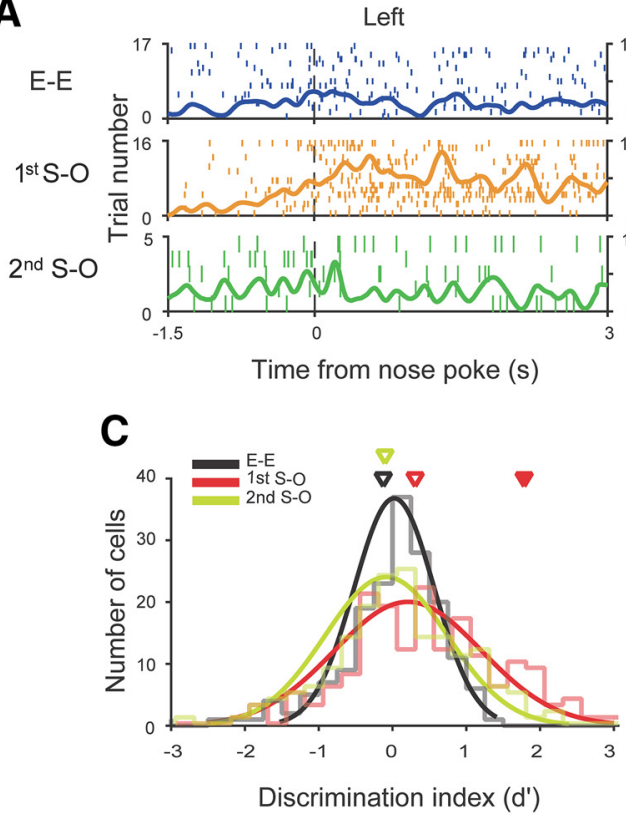

B

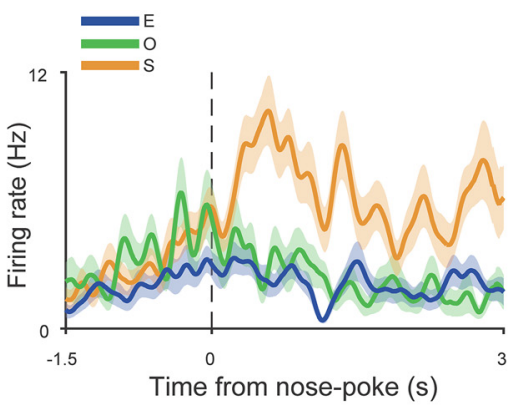

Time from nose poke $(\mathrm{s})$

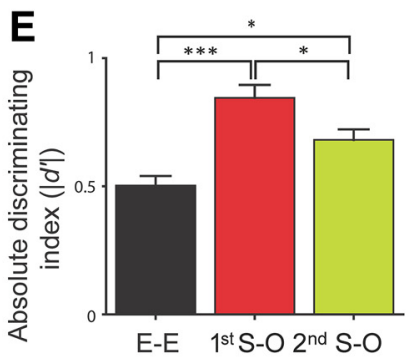

Figure 2. Social target-selective neuronal responses during nose poke. $A, B$, An example of a social target-selective neuron. $A$, Spike raster plots and SDFs are shown overlaid for all valid nose-poke trials. $\boldsymbol{B}$, Nose-poke responses (SDFs) to each target averaged across sessions. Shading indicates \pm SEM. C $\boldsymbol{E}$, Population data for all analyzed neurons $(n=176)$. C, Distributions of discriminability $\left(d^{\prime}\right)$ between two targets (curves, Gaussian fitting). Positive and negative $d^{\prime}$ values of S- 0 sessions indicate preferential responses to the social and object target, respectively. Empty triangles, mean $d^{\prime}$ values; filled triangle, $d^{\prime}$ value of the example neuron shown in $\boldsymbol{A}, \boldsymbol{B}$. D. The $d^{\prime}$ values for the three sessions, presented as means \pm SEM. $E$, Absolute $d^{\prime}$ values (discriminability without consideration of response direction; ${ }^{*} p<0.05$, ${ }^{* * *} p<0.001$; ns, not significant; one-way ANOVA with Tukey's post hoc test).

hibited enhanced responses to the social target such that their averaged response to the social target, including all session data in the analysis, was greater than that to the other targets (Fig. $3 B, C$ ). A separate examination of data from each session revealed that their responses to the social target were more prominent during the first than the second S-O session (Fig. 3D).

To further examine relative contributions of stimulus type, spatial location, and session (first vs second S-O) to discharges of mPFC neurons, we performed a three-way ANOVA, plotting $F$ values of all mPFC neurons in two-dimensional space as stimulus-versus-spatial and stimulus-versus-session factor plots (the spatial-versus-session factor plot is not shown). Some neurons showed stronger dependence on stimulus type than spatial (or session) factor, but others showed the opposite pattern (Fig. $3 E, F)$, consistent with the results shown in Figure $3 A$. In the case of the 24 social target-selective neurons, neuronal activity was primarily accounted for by the stimulus type rather than spatial location or session (Fig. 3E,F). These results confirm that the activity of social target-selective neurons was most strongly influenced by the stimulus type rather than the spatial or session factor. However, 15 of the 24 neurons (62.5\%) exhibited a significant reduction in their firing rates during the second session compared with the first (main effect of session, $p<0.05$ ). Nine of the social-selective neurons (37.5\%) showed significant spatial location-dependent firing as well (main effect of spatial location, $p<0.05$ ). Thus, social target-selective responses were reduced across the first and second S-O sessions, similar to the reduced social approach behaviors across the two $\mathrm{S}-\mathrm{O}$ sessions (Fig. $1 B-E$ ).

The remaining neurons (i.e., not social target-selective) showed diverse response patterns (Figs. $3 A, 4$ ). To compare these neurons with social target-selective neurons, we examined responses of object target-selective neurons, determined in the same manner as for social target-selective neurons. Of the 176
mPFC neurons, $15(8.5 \%)$ showed significant differences in social-versus-object and object-versus-empty responses (Figs. $3 A, 5 A)$, of which $13(7.4 \%)$ showed consistently higher or lower firing rates to the object compared with social and empty targets; these were determined to be object target-selective neurons (Fig. $5 A$, neurons in the first and third quadrants). Nine object targetselective neurons showed higher rates in response to the object compared with the other targets (Fig. 5C), and four exhibited lower rates (Fig. $5 G$; no significant deviation from equal distribution; $p=0.473$, Fisher's exact test). Unlike the social targetselective neurons, the mean normalized firing rates of these latter neurons was not elevated above the baseline level (before nose poke) on exposure to the object stimulus (Fig. 5B). Diverse response patterns were observed for the remaining neurons that were not object target selective (Fig. $5 D-F, H-J$ ).

\section{Neuronal activity in the in-zone area}

Units that emitted spikes in all three experimental sessions with overall mean discharge rates $>0.5 \mathrm{~Hz}$ during the in-zone period were included in the analysis (178 of 248 units; Table 1). As indicated in Figure 6, which presents some of the main findings, the results were similar to those obtained for the nose-poke period analysis (Fig. 6). Almost all (23 of 24; $95.8 \%$ ) of the social target-selective neurons displayed enhanced responses to the social target, with greater averaged responses relative to the other targets (Fig. $6 A-C$ ). An analysis of in-zone period activity of all neurons $(n=178)$ revealed elevated responses to the social stimulus relative to the object stimulus during the first $\mathrm{S}-\mathrm{O}$ session, as demonstrated by oneway ANOVA $\left(F_{(2,177)}=9.7, p<0.001\right)$ and Tukey's post hoc test (E-E vs first S-O, $p<0.001$; E-E vs second $\mathrm{S}-\mathrm{O}, p=0.756$; first $\mathrm{S}-\mathrm{O}$ vs second $\mathrm{S}-\mathrm{O}, p=0.002$; Fig. $6 D$ ). 
A

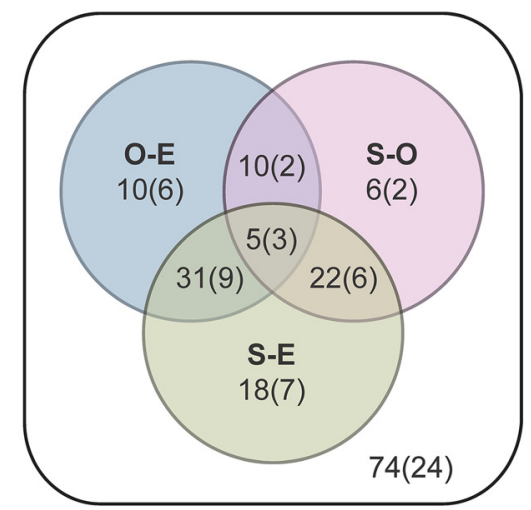

C

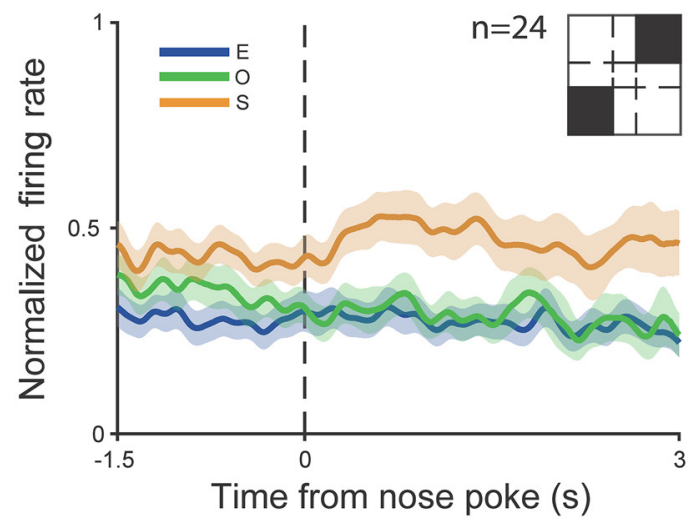

E

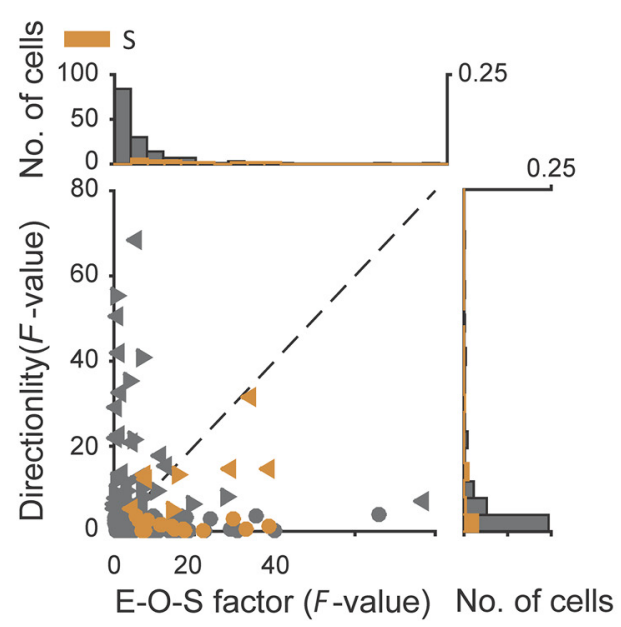

B
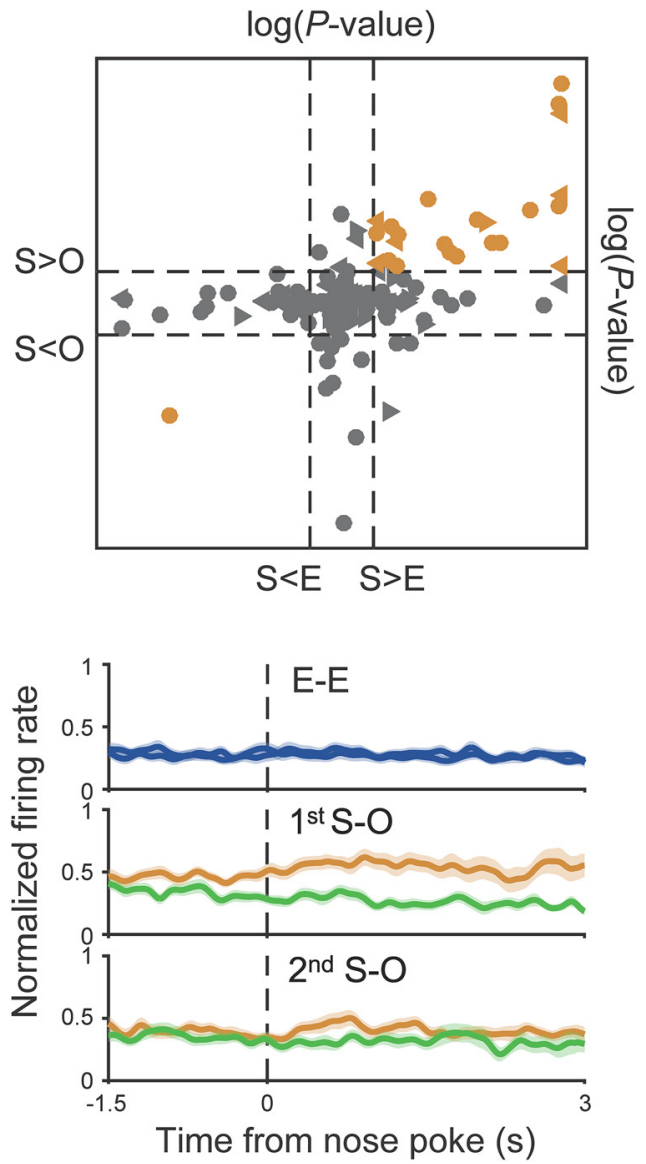

$\mathbf{F}$

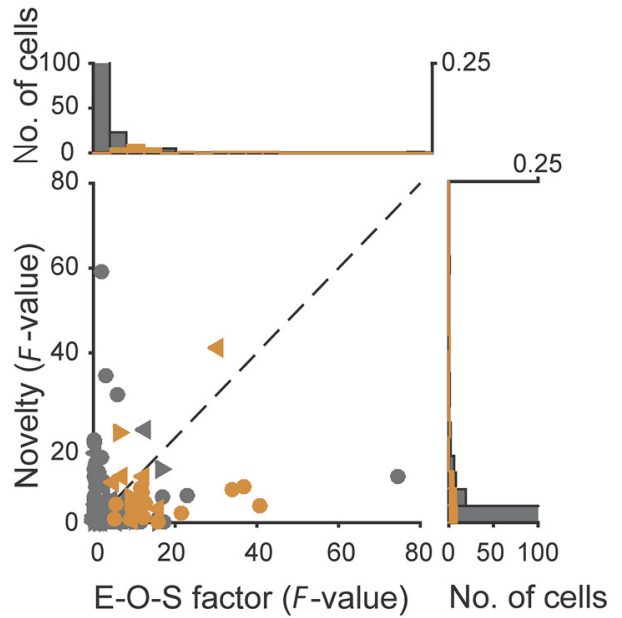

Figure 3. Discharge characteristics of social target-selective neurons. Social target-selective neurons were determined based on neural activity during the nose-poke period. $\boldsymbol{A}$, Types of neurons that discriminated between different types of stimulus (social, object, and empty targets) were determined using a two-way ANOVA (main factors, stimulus type, and spatial location). The Venn diagram shows the numbers of neurons whose firing rates were different between two stimulus types (Tukey's post hoc test), and the numbers in parentheses indicate those neurons that also showed spatial (left vs right) selectivity. The numbers outside of the circles indicate those neurons that showed no target specificity (total, $n=74 ;$ those with spatial selectivity, $n=24$ ). $\boldsymbol{B}, p$ values for social-versus-object and social-versus-empty discriminations (two-way ANOVA with Tukey's post hoc test) for all neurons ( $n=176$ ), presented in log scale (dashed lines, $p=0.05$ ). Twenty-four neurons (orange) were determined to be social target-selective neurons (circles within the first and third quadrants). $\boldsymbol{C}, \boldsymbol{D}$, Averaged responses (shading, \pm SEM) to each stimulus ( $\boldsymbol{C}$, across sessions; $\boldsymbol{D}$, within sessions). $\boldsymbol{E}, \boldsymbol{F}$, The distribution of $F$ values for each factor (3-way ANOVA) was compared between stimulus type (E-0-S factor) and spatial location (left-right directionality factor; $\boldsymbol{E}$ ) and between stimulus type and session (novelty factor; $\boldsymbol{F}$ ). Orange symbols denote the 24 total social target-selective neurons during nose poke, and gray symbols represent the remaining neurons. Triangles indicate those neurons with significant spatial selectivity. Frequency histograms of $F$ values are shown for the social target-selective and remaining neurons in orange and gray colors, respectively, on top and right for the corresponding factor. Neural data from all three sessions were analyzed together except in $\boldsymbol{D}$.

\section{Spatial firing}

We also examined the relationship between neuronal activity and the distance from a chamber. Analyses of both nose-poke period and in-zone area identified 24 neurons as social target selective.
Of these, $20(83.3 \%)$ were social target-selective neurons in both analyses. Thus, 28 neurons were determined to be social targetselective neurons in at least one analysis. An examination of spatial firing patterns of these neurons showed that their discharge 

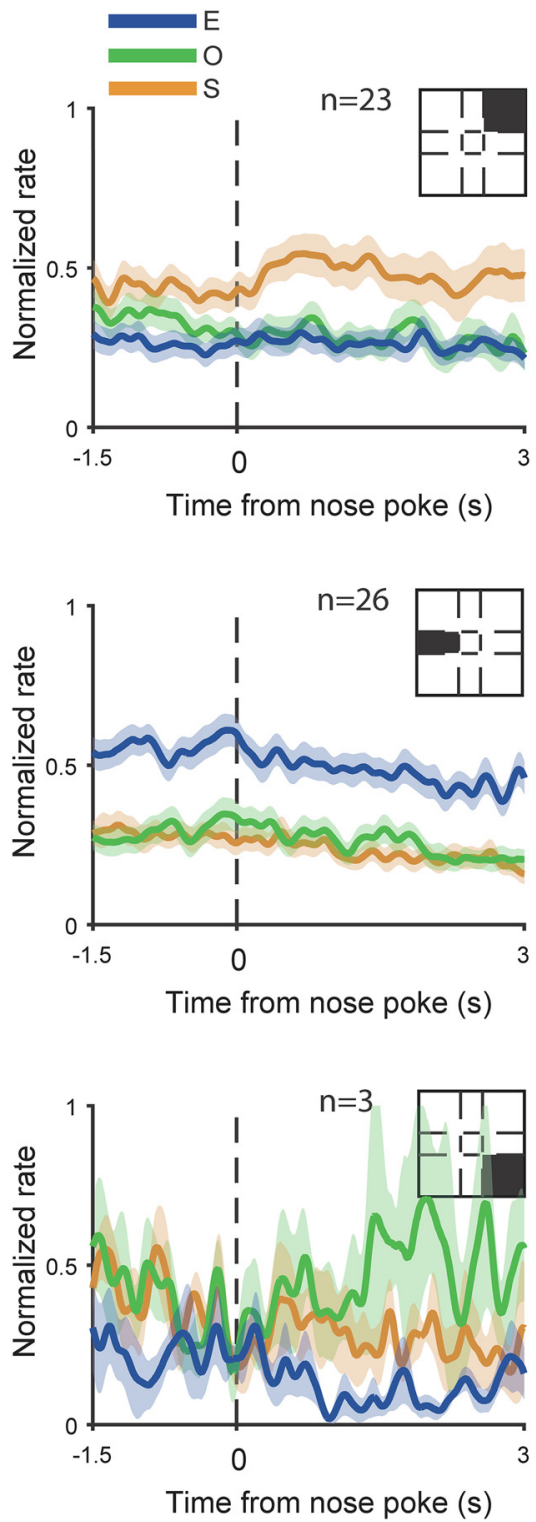
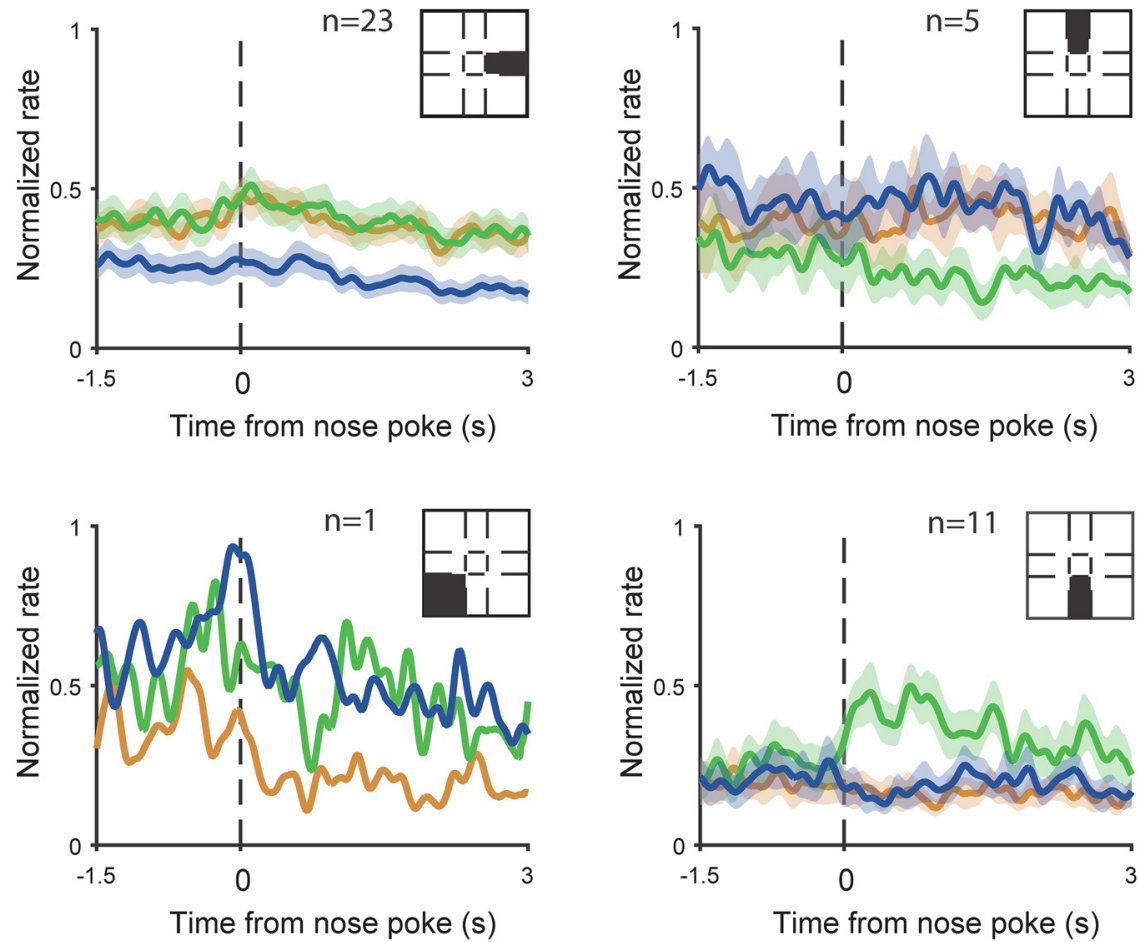

Figure 4. Diverse responses of $\mathrm{mPFC}$ neurons. Mean normalized firing rates during nose poke are shown for different types of neurons. Inset squares correspond to the log( $p$ value) square in Figure $3 B$. The same format as in Figure $3 C$.

rates gradually increased as the subject mouse approached the social target during the first S-O session $(p<0.001)$ but not during the E-E $(p=0.854)$ or second S-O $(p=0.082)$ session (Fig. 7, linear regression analysis).

\section{Responses of different cell types to the social target}

We classified the recorded neurons into wide-spike neurons (putative pyramidal cells) and narrow-spike neurons (putative interneurons) based on widths and peak-to-valley ratios of filtered spike waveforms (Fig. $8 A$ ). Wide-spike neurons tended to fire at lower rates $(n=183,0.933 \pm 0.088 \mathrm{~Hz}$, mean $\pm \mathrm{SD})$ than narrow-spike neurons $(n=65,1.179 \pm$ $0.243 \mathrm{~Hz}$ ). To test whether the two cell types show different social target-related responses, we compared their responses during the nose-poke period. The discrimination index $\left(d^{\prime}\right)$ between social and object targets, obtained by analyzing both the first and second S-O sessions, was similar for the two cell groups (Fig. $8 B$ ). Of the 24 social target-selective neurons, 20 were wide-spike neurons and four were narrow-spike neu- rons. Both groups of cells exhibited enhanced responses during nose poking of the social target (Fig. $8 C, D$ ). Similar results were obtained for the in-zone area analysis (data not shown). These results indicate that putative pyramidal cells and interneurons tend to show similar responses to the social target.

\section{Discussion}

As a first step toward elucidating mPFC neural correlates of mouse social behavior, we examined $\mathrm{MPFC}$ neuronal activity in a modified version of the three-chamber test. We found that a subset of mPFC neurons exhibited elevated discharge rates during exploration of a social object relative to an inanimate object or an empty target, a result that could not be accounted for by direction-selective firing. In addition, social targetselective responses were more prominent during the first than the second $\mathrm{S}-\mathrm{O}$ session, as was also the case for social approach behaviors. 
A

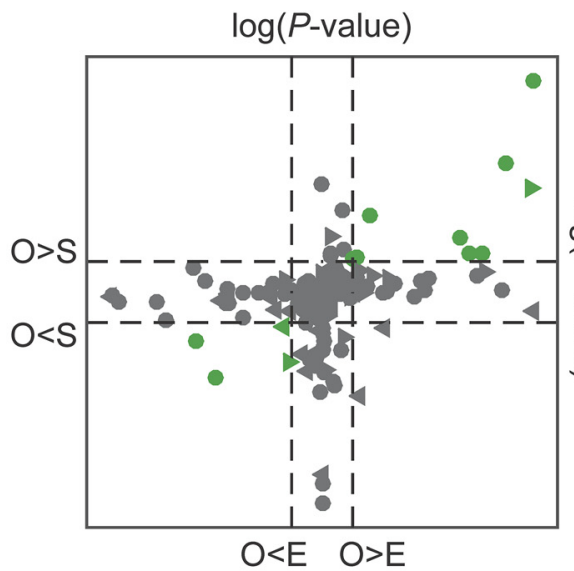

B

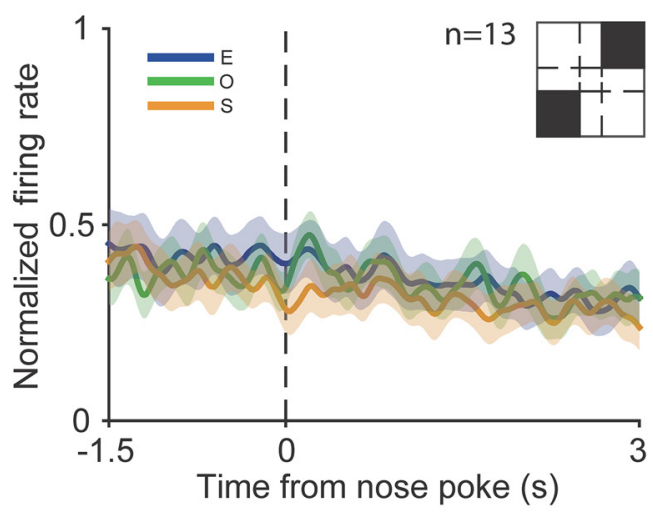

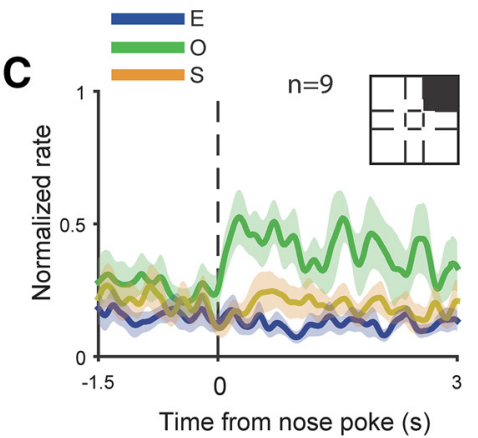

D

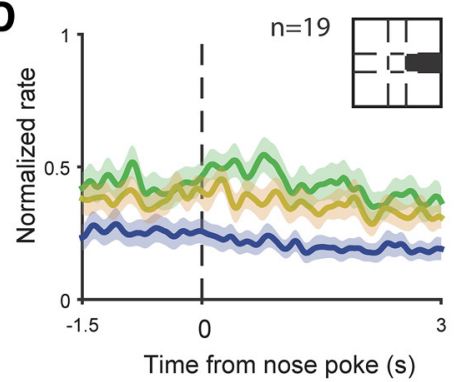

$\mathbf{F}$

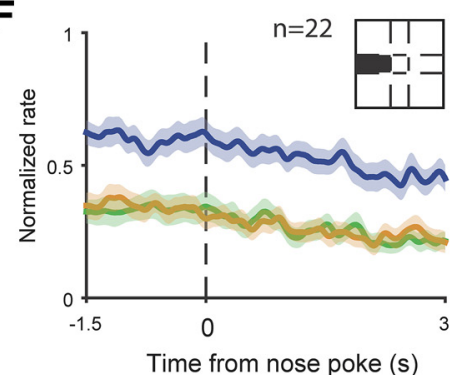

I

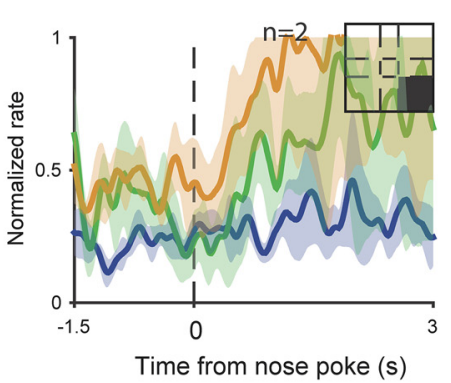

G

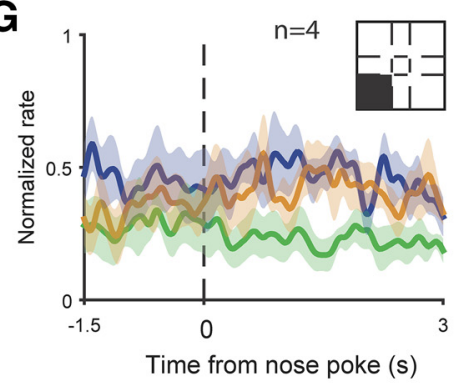

J

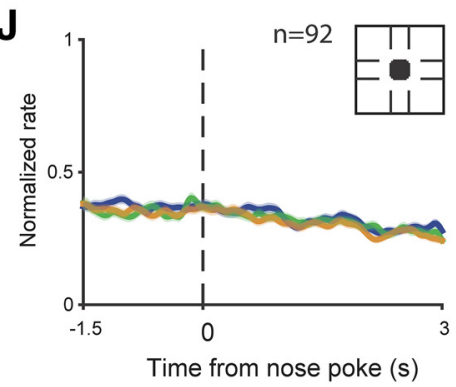

E

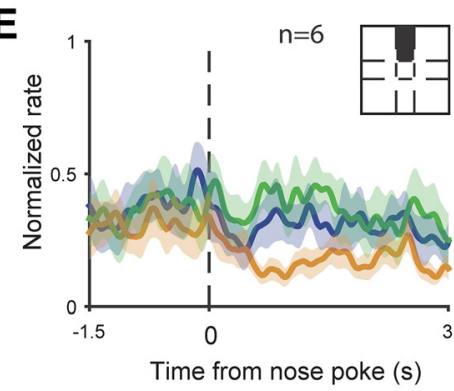

$\mathbf{H}$

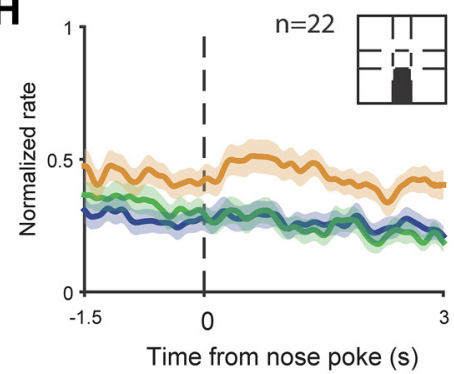

Figure 5. Discharge characteristics of object target-selective neurons. Object target-selective neurons were determined based on neural activity during the nose-poke period. $A, p$ values for object-versus-social and object-versus-empty discriminations (two-way ANOVA with Tukey's post hoc test) for all neurons $(n=176)$, drawn in log scale (dashed lines, $p=0.05$ ). Thirteen neurons (green) were determined to be object target-selective neurons (circles within the first and third quadrants). $\boldsymbol{B}$, Averaged responses (shading, \pm SEM) to each stimulus. The same format as in Figure 3C. $(-J$, Mean normalized firing rates during nose poke are shown for different types of neurons. Inset squares correspond to the $\log (p$ value) square in $A$. The same format as in Figure $3 B$.

In the three-chamber test, the time spent in two side chambers is known to be the most important parameter (Yang et al., 2011). However, in the present study, we were compelled to remove the chamber walls for the purpose of in vivo recording; thus, there were no side chambers with dividing walls. As a potential alternative measure of chamber time, we used in-zone time, which provided data in addition to sniffing time for assessing the social interaction of mice. We found that the activity of some mPFC neurons increased during interaction with the social target, regardless of which dataset was analyzed. Of 28 neurons that were determined to be social target selective based on either nose-poke period or in-zone area analysis, 20 showed increased discharge rates in both nose-poke and in-zone areas of the social target. Thus, the two groups of neurons mostly overlapped. A spatial firing analysis showed that the discharge rates of social targetselective neurons also gradually increased as the subject mouse 
A

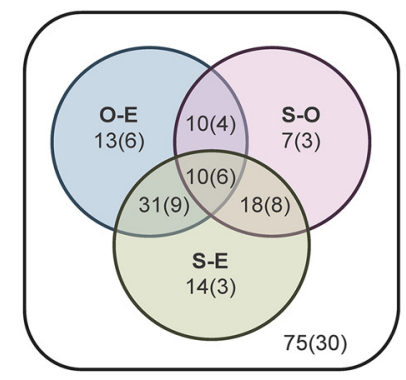

C

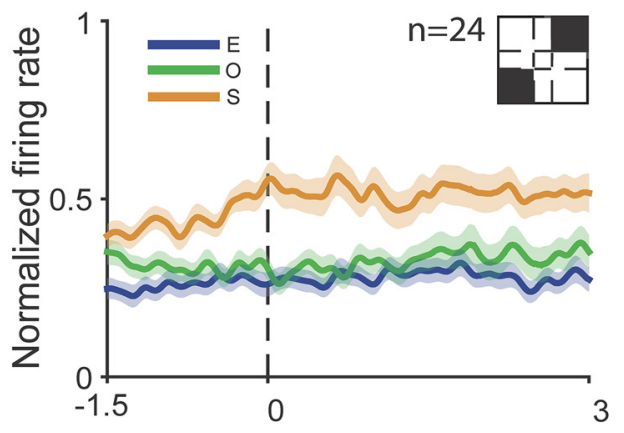

Time from zone entry (s)
B

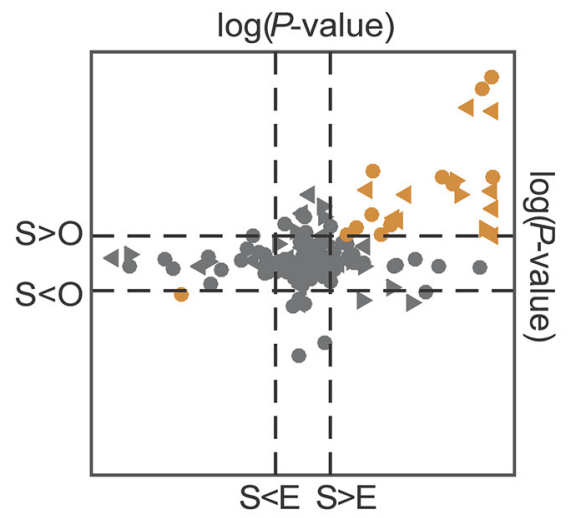

D

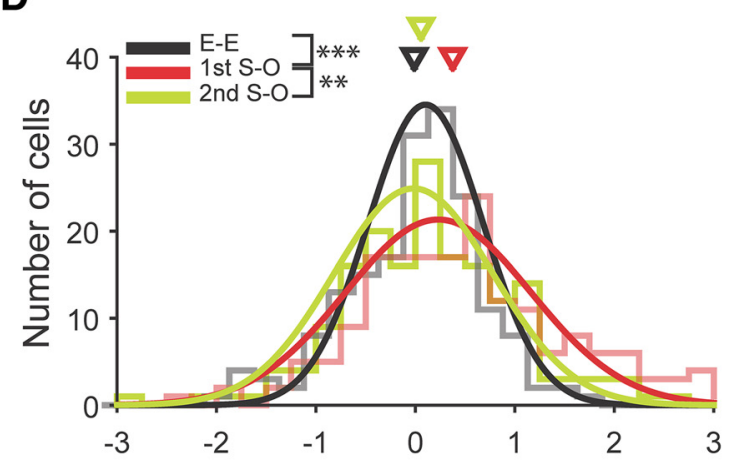

Discrimination index $\left(d^{\prime}\right)$

Figure 6. Social target-selective neuronal responses in the in-zone area. Analysis of in-zone neural data yielded similar results as the analysis of nose-poke neural data. $A-C$, Follows format of Figure $3 A-C . D$, Follows format of Figure $2 C$.

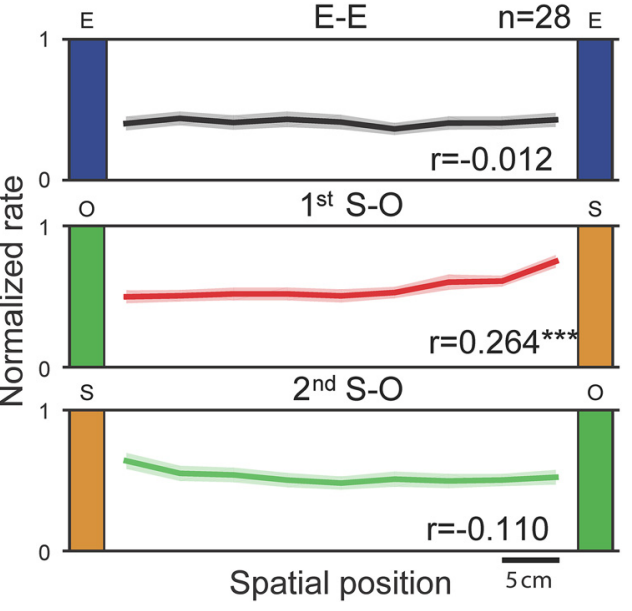

Figure 7. Spatial firing of social target-selective neurons. Spatial firing rates of the 28 neurons determined to be social-selective neurons in nose-poke or in-zone area analyses, presented as means \pm SEM. $r$, Slope of linear regression. ${ }^{* * *} p<0.001$.

approached the social target. These results indicate that social target-selective responses of individual $\mathrm{mPFC}$ neurons are robust.

It is unclear which sensory cues (e.g., movement, sound, smell) emitted by a stranger mouse played the major role in eliciting $\mathrm{mPFC}$ neuronal responses and approach behaviors. The social target-selective responses may be heavily contributed by smell-dependent firing (Ryan et al., 2008). However, enhanced responses to the social target were observed, albeit weakly, even during the second S-O session. If odor traces from fur, urine, and/or feces primarily affected neuronal responses during the first S-O session, it would be difficult for a social target to elicit stronger neuronal responses than the object target after swapping their positions (i.e., second S-O session). In addition, olfactory habituation happens quickly (Yang and Crawley, 2009), and our chamber was relatively small. These considerations cast doubt on the possibility that social target-selective responses represent purely sensory responses to the smell of the target mouse. Unfortunately, odor gradients were not measured in the present study. In future studies, examining social target-selective mPFC neuronal responses together with temporal dynamics of spatial odor gradients will help resolve this issue.

All three analyses - nose poke, in-zone, and spatial firingconverged to show robust, enhanced social target-selective responses in some mPFC neurons, arguing against the possibility that social target-selective responses represent simple responses to a single sensory cue. In addition, social target-selective neuronal responses decreased substantially across the first and second $\mathrm{S}-\mathrm{O}$ sessions in parallel with social approach behaviors. Because we analyzed neural activity during the same behaviors (nose poke and in-zone area duration) across sessions, these results further suggest that social target-related $\mathrm{mPFC}$ neuronal responses do not merely represent simple sensory responses. It is likely that social approach behaviors depend not only on immediate sensory information but also on the memory of a previously encountered social target. Likewise, social target-selective mPFC responses may depend on sensory information and memory. The rodent $\mathrm{mPFC}$ is known to play an important role in working memory (Vertes, 2006; Kesner and Churchwell, 2011). Sensory cues may 
A

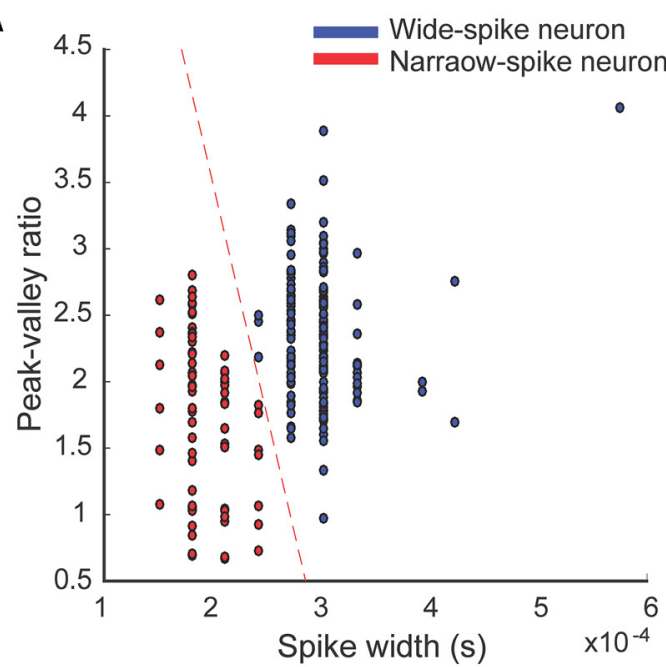

C

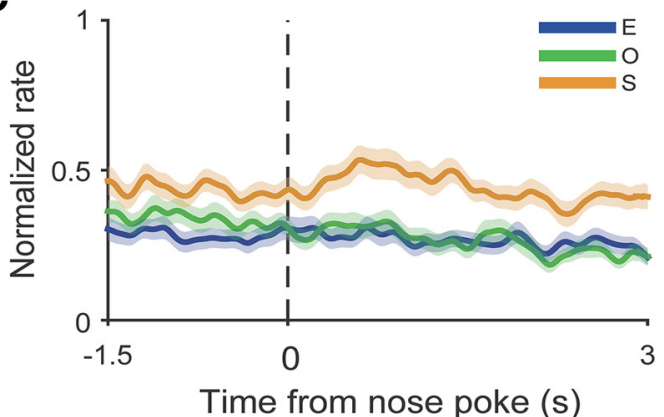

B

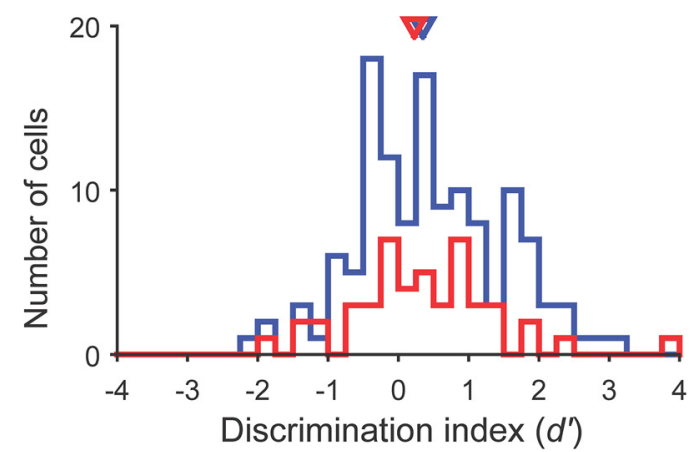

D

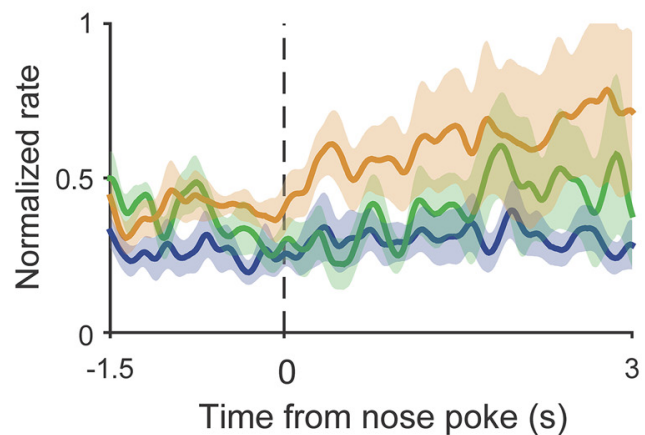

Figure 8. Responses of different cell types to the social target. $A$, Unit classification. The recorded mPFC units ( $n=248$ ) were classified into wide-spike neurons (putative pyramidal cells; blue) and narrow-spike neurons (putative interneurons; red) based on the width and peak-to-valley ratio of the averaged spike waveform. 0 fthe $248 \mathrm{mPFC}$ units, 183 (73.8\%) were classified as wide-spike neurons and 65 (26.2\%) as narrow-spike neurons. B, Comparison of the discrimination index $\left(d^{\prime}\right)$ during the nose-poke period for wide-spike and narrow-spike neurons showed no significant difference ( $p=0.439, t$ test). $\boldsymbol{C}, \boldsymbol{D}$, SDFs of social target-selective neurons during the nose-poke period are shown separately for wide-spike neurons $(n=20 ; C)$ and narrow-spike neurons $(n=4 ; \boldsymbol{D})$.

be important for the initial recognition of a stranger mouse as a social target, but their importance for eliciting social approach behaviors and social target-selective mPFC responses may diminish in the late phase of a session.

It remains to be determined whether elevated $\mathrm{mPFC}$ responses to the social target are related to stimulus salience or "social" stimulus. It is also unknown to which aspects of social approach behaviors the observed mPFC neuronal activity is related. Social approach behaviors are likely to consist of multiple processes, including sensory integration, social perception, and sensory-motor transformation. Memory is also likely to play a role in social approach behaviors. Future studies should address which aspect of these processes the enhanced mPFC neuronal activity represents.

In conclusion, we found that the activity of some mPFC neurons in a test mouse increased during the approach to a stranger mouse but not during the approach to an inanimate object or an empty chamber. It is currently unclear which sensory stimuli elicit the responses. Moreover, whether the responses represent genuine social responses, and if so, to which aspects of social behaviors they are related, are similarly unclear. Nevertheless, our results reveal social target-selective neuronal activity in the $\mathrm{mPFC}$ in a widely used social-interaction paradigm. These findings may prove helpful for future studies of neural correlates of social interaction in health and disease and neurobiological studies of animals with impaired social interaction.

\section{References}

Barnes SA, Pinto-Duarte A, Kappe A, Zembrzycki A, Metzler A, Mukamel EA, Lucero J, Wang X, Sejnowski TJ, Markou A, Behrens MM (2015) Disruption of mGluR5 in parvalbumin-positive interneurons induces core features of neurodevelopmental disorders. Mol Psychiatry 20:1161-1172. CrossRef Medline

Bey AL, Jiang YH (2001) Overview of mouse models of autism spectrum disorders current protocols in pharmacology. Hoboken, NJ: Wiley.

Chaudhury D, Walsh JJ, Friedman AK, Juarez B, Ku SM, Koo JW, Ferguson D, Tsai HC, Pomeranz L, Christoffel DJ, Nectow AR, Ekstrand M, Domingos A, Mazei-Robison MS, Mouzon E, Lobo MK, Neve RL, Friedman JM, Russo SJ, Deisseroth K, Nestler EJ, Han MH (2013) Rapid regulation of depression-related behaviours by control of midbrain dopamine neurons. Nature 493:532-536. CrossRef Medline

Chung W, Choi SY, Lee E, Park H, Kang J, Park H, Choi Y, Lee D, Park SG, Kim R, Cho YS, Choi J, Kim MH, Lee JW, Lee S, Rhim I, Jung MW, Kim D, Bae YC, Kim E (2015) Social deficits in IRSp53 mutant mice improved by NMDAR and mGluR5 suppression. Nat Neurosci 18:435-443. CrossRef Medline

Covington HE 3rd, Lobo MK, Maze I, Vialou V, Hyman JM, Zaman S, LaPlant Q, Mouzon E, Ghose S, Tamminga CA, Neve RL, Deisseroth K, Nestler EJ (2010) Antidepressant effect of optogenetics stimulation of the medial prefrontal cortex. J Neurosci 30:16082-16090. CrossRef Medline

Crawley JN (2004) Designing mouse behavioral tasks relevant to autisticlike behaviors. Ment Retard Dev Disabil Res Rev 10:248-258. CrossRef Medline

Del Pino I, García-Frigola C, Dehorter N, Brotons-Mas JR, AlvarezSalvado E, Martínez de Lagrán M, Ciceri G, Gabaldón MV, Moratal D, 
Dierssen M, Canals S, Marín O, Rico B (2013) Erbb4 deletion from fast-spiking interneurons causes schizophrenia-like phenotypes. Neuron 79:1152-1168. CrossRef Medline

Duffney LJ, Zhong P, Wei J, Matas E, Cheng J, Qin L, Ma K, Dietz DM, Kajiwara Y, Buxbaum JD, Yan Z (2015) Autism-like deficits in Shank3deficient mice are rescued by targeting actin regulators. Cell Rep 11: 1400-1413. CrossRef Medline

Grayton HM, Missler M, Collier DA, Fernandes C (2013) Altered social behaviours in neurexin $1 \alpha$ knockout mice resemble core symptoms in neurodevelopmental disorders. PLoS One 8:e67114. CrossRef Medline

Huang TN, Chuang HC, Chou WH, Chen CY, Wang HF, Chou SJ, Hsueh YP (2014) Tbr1 haploinsufficiency impairs amygdalar axonal projections and results in cognitive abnormality. Nat Neurosci 17:240-247. CrossRef Medline

Jodo E, Katayama T, Okamoto M, Suzuki Y, Hoshino K, Kayama Y (2010) Differences in responsiveness of mediodorsal thalamic and medial prefrontal cortical neurons to social interaction and systemically administered phencyclidine in rats. Neuroscience 170:1153-1164. CrossRef Medline

Kazdoba TM, Leach PT, Crawley JN (2016) Behavioral phenotypes of genetic mouse models of autism. Genes Brain Behav 15:7-26. CrossRef Medline

Kesner RP, Churchwell JC (2011) An analysis of rat prefrontal cortex in mediating executive function. Neurobiol Learn Mem 96:417-431. CrossRef Medline

Kleijer KT, Schmeisser MJ, Krueger DD, Boeckers TM, Scheiffele P, Bourgeron T, Brose N, Burbach JP (2014) Neurobiology of autism gene products: towards pathogenesis and drug targets. Psychopharmacology 231:1037-1062. CrossRef Medline

Latimer KW, Yates JL, Meister ML, Huk AC, Pillow JW (2015) Single-trial spike trains in parietal cortex reveal discrete steps during decisionmaking. Science 349:184-187. CrossRef Medline

Lee E, Hong J, Park YG, Chae S, Kim Y, Kim D (2015) Left brain cortical activity modulates stress effects on social behavior. Sci Rep 5:13342. CrossRef Medline

Liang J, Xu W, Hsu YT, Yee AX, Chen L, Südhof TC (2015) Conditional neuroligin-2 knockout in adult medial prefrontal cortex links chronic changes in synaptic inhibition to cognitive impairments. Mol Psychiatry 20:850-859. CrossRef Medline
Li N, Lee B, Liu RJ, Banasr M, Dwyer JM, Iwata M, Li XY, Aghajanian G, Duman RS (2010) mTOR-dependent synapse formation underlies the rapid antidepressant effects of NMDA antagonists. Science 329:959-964. CrossRef Medline

Lombardi LM, Baker SA, Zoghbi HY (2015) MECP2 disorders: from the clinic to mice and back. J Clin Invest 125:2914-2923. CrossRef Medline

Macmillan NA, Creelman CD (2004) Detection theory; a user's guide. Ed 2. Cambridge, UK: Psychology Press.

Nguyen R, Morrissey MD, Mahadevan V, Cajanding JD, Woodin MA, Yeomans JS, Takehara-Nishiuchi K, Kim JC (2014) Parvalbumin and GAD65 interneuron inhibition in the ventral hippocampus induces distinct behavioral deficits relevant to schizophrenia. J Neurosci 34:14948 14960. CrossRef Medline

Ryan BC, Young NB, Moy SS, Crawley JN (2008) Olfactory cues are sufficient to elicit social approach behaviors but not social transmission of food preference in C57BL/6J mice. Behav Brain Res 193:235242. CrossRef Medline

Ting JT, Peça J, Feng G (2012) Functional consequences of mutations in postsynaptic scaffolding proteins and relevance to psychiatric disorders. Annu Rev Neurosci 35:49-71. CrossRef Medline

Vertes RP (2006) Interactions among the medial prefrontal cortex, hippocampus and midline thalamus in emotional and cognitive processing in the rat. Neuroscience 142:1-20. CrossRef Medline

Won H, Lee HR, Gee HY, Mah W, Kim JI, Lee J, Ha S, Chung C, Jung ES, Cho YS, Park SG, Lee JS, Lee K, Kim D, Bae YC, Kaang BK, Lee MG, Kim E (2012) Autistic-like social behaviour in Shank2-mutant mice improved by restoring NMDA receptor function. Nature 486:261-265. CrossRef Medline

Yang M, Crawley JN (2009) Simple behavioral assessment of mouse olfaction. Curr Protoc Neurosci Chapter 8:Unit 8.24. CrossRef Medline

Yang M, Silverman JL, Crawley JN (2011) Automated three-chambered social approach task for mice. Curr Protoc Neurosci Chapter 8:Unit 8.26. CrossRef Medline

Yizhar O, Fenno LE, Prigge M, Schneider F, Davidson TJ, O'Shea DJ, Sohal VS, Goshen I, Finkelstein J, Paz JT, Stehfest K, Fudim R, Ramakrishnan C, Huguenard JR, Hegemann P, Deisseroth K (2011) Neocortical excitation/inhibition balance in information processing and social dysfunction. Nature 477:171-178. CrossRef Medline 